\title{
Investigation of Total Losses of Non-Oriented Electrical Steels
}

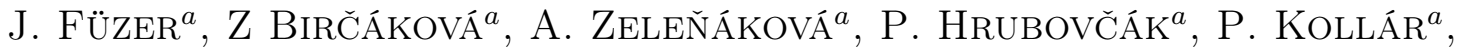 \\ M. PREDMERSKY ${ }^{b}$ AND J. HuŇADY ${ }^{b}$ \\ ${ }^{a}$ Institute of Physics, Faculty of Science, P.J. Šafárik University, Park Angelinum 9, 04154 Košice, Slovakia \\ ${ }^{b}$ U.S. Steel Košice, s.r.o., Vstupný areál U.S. Steel, 04454 Košice, Slovakia \\ The aim of this work was to investigate the influence of microstructural features on the soft magnetic \\ properties. The materials chosen for this work were two types of the Epstein strips of commercially produced \\ non-oriented electrical steels by U.S. Steel Košice. The AC magnetic properties in $0.2-100 \mathrm{~Hz}$ frequency range \\ were obtained by measurements of AC hysteresis loops by a fluxmeter based non-standard single sheet AC \\ hysteresisgraph. The influence of the grain size and magnetic domains structure on the partial contributions \\ (hysteresis, eddy current and anomalous) to the total losses is also discussed. The results of the frequency \\ dependence of the total losses, measured by a single sheet loop tracer along the rolling direction and perpendicular \\ to the rolling direction, show different contribution of partial components.
}

PACS numbers: $75.50 . \mathrm{Bb}, 75.60 .-\mathrm{d}$

\section{Introduction}

Non-oriented steel (NO) sheets are materials with great engineering significance used in AC applications where the direction of magnetic flux is circular, such as electric motors and generators [1]. The understanding of the dependence of power losses in electrical steels on frequency is of great importance [2]. A tool for estimating losses at different frequencies is the statistical loss theory [3]. For producers of the steel it gives an insight how to reduce a loss. For users of the steels, it helps to estimate the loss at various working conditions. The core losses of NO electrical steel laminations under sinusoidal voltage excitations at frequency range from $0.4 \mathrm{~Hz}$ to $100 \mathrm{~Hz}$ are analyzed in the paper.

\section{Experimental}

Steel samples S242 and S096 (28 cm long and $3 \mathrm{~cm}$ wide) NO electrical steel (U.S. Steel Košice, s.r.o.) were cut parallel (longitudinal or L-samples) as well as perpendicular (transversal or T-samples) to the rolling direction. Table I summarizes the chemical composition of the investigated steel samples. For investigating the mi-

TABLE I

Chemical composition (wt\%) of the investigated steel samples. The reminder to $100 \%$ is Fe.

\begin{tabular}{c|c|c|c|c|c}
\hline \hline Element & $\mathrm{Si}$ & $\mathrm{P}$ & $\mathrm{S}$ & $\mathrm{Al}$ & $\mathrm{N}$ \\
\hline $\mathrm{S} 242$ & 2.42 & 0.009 & 0.0034 & 0.40 & 0.0015 \\
$\mathrm{~S} 096$ & 0.96 & 0.086 & 0.0088 & 0.12 & 0.0021
\end{tabular}

crostructure and the domains the surface was mechanically and electrolytically polished. A thin layer of colloidal suspension of magnetic particles was placed on the specimen surface and the domain pattern was observed using optical microscope. Magnetic force microscopy (MFM) characterization was performed using Veeco Nanoscope controller and Dimension Icon microscope. The specific electrical resistivity of the NO electrical steels was measured by the direct method. The hysteresis loops of NO electrical steel were measured using fluxmeter based one sheet tester hysteresisgraph in the frequency range $0.4-100 \mathrm{~Hz}$ at maximum flux density of $1.5 \mathrm{~T}$.

\section{Results and discussion}

Sample S242 consists of the inhomogeneous grains with the mean planar grain diameter along the rolling direction of $110 \mu \mathrm{m}$. Domain structure shows the small wave domains elongated with the average domains wide of about $1 \mu \mathrm{m}$. Sample S096 consists of the smaller homogeneous grains with the mean planar grain diameter of $30 \mu \mathrm{m}$. Domain structure shows more complicated and branched patterns with the average domain size about $1.9 \mu \mathrm{m}$.

The iron loss consists of hysteresis loss, classical eddy current loss, and anomalous loss. The following empirical equation is often quoted for the total hysteresis power loss at given magnetizing frequency $f$ :

$$
P_{\mathrm{h}}=K_{\mathrm{h}} f\left(B_{\mathrm{m}}\right)^{x},
$$

where $B_{\mathrm{m}}$ is the peak flux density, and $K_{\mathrm{h}}$ and $x$ are parameters that depend on the material factors. It is mostly related to the microstructure of the steel. The classical eddy current power losses in a thin lamination at magnetizing frequency $f$ is calculated from

$$
P_{\mathrm{e}}=\frac{\pi^{2}\left(B_{\mathrm{m}} f d\right)^{2}}{6 \rho},
$$

where $d$ is the lamination thickness and $\rho$ is its specific electrical resistivity. A commonly used equation for estimating the anomalous loss under sinusoidal flux is written as [3]

$$
P_{\mathrm{a}}=8.8 \sqrt{\sigma G S V_{0}}\left(B_{\mathrm{m}} f\right)^{3 / 2},
$$

where $\sigma$ is the conductivity, $S$ is the cross-section area of the material, and $G$ and $V_{0}$ are parameters which are material and magnetization dependent. The components could be written in terms of energy loss per cycle as

$$
P / f=C_{0}+C_{1} f+C_{2} f^{1 / 2},
$$

where $C_{0}, C_{1}$, and $C_{2}$ are constant for a given flux density and frequency. 


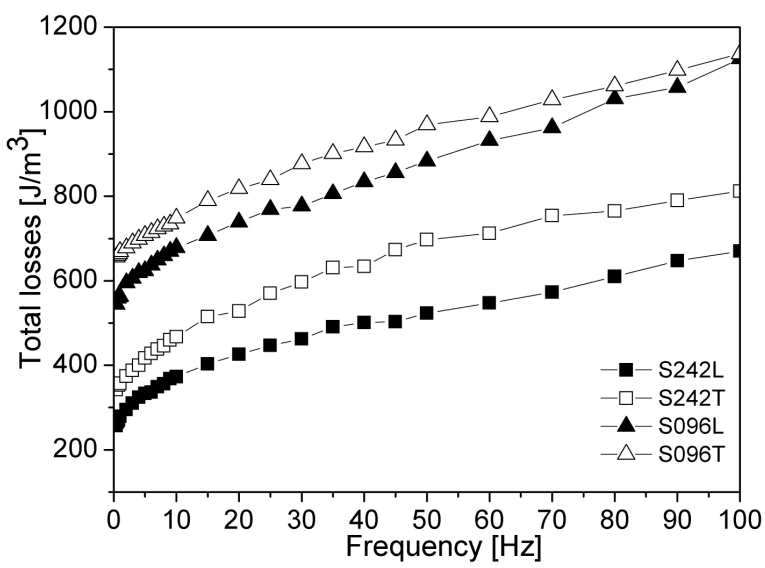

Fig. 1. Total power loss as a function of magnetizing frequency in $\mathrm{NO}$ electrical steel samples at $B_{\max }=$ $1.5 \mathrm{~T}, f=50 \mathrm{~Hz}$.

The dependence of total loss on the frequency is shown in Fig. 1. Loss components are shown in Fig. 2. Total loss is calculated from measured hysteresis loops. Hysteresis loss is obtained by extrapolation of the total loss frequency dependence to $f=0$. Classical loss is calculated using Eq. (2) and anomalous loss is calculated as a reminder loss to the total loss knowing hysteresis and classical losses. This result suggests that a reduc- tion in the grain size increases the hysteresis loss due to increasing number of pinning centers from grain boundaries. On the other hand, the anomalous loss is reduced when the grain size is reduced. Similar observations have been made before [4]. The results of measurements are summarized in Table II.

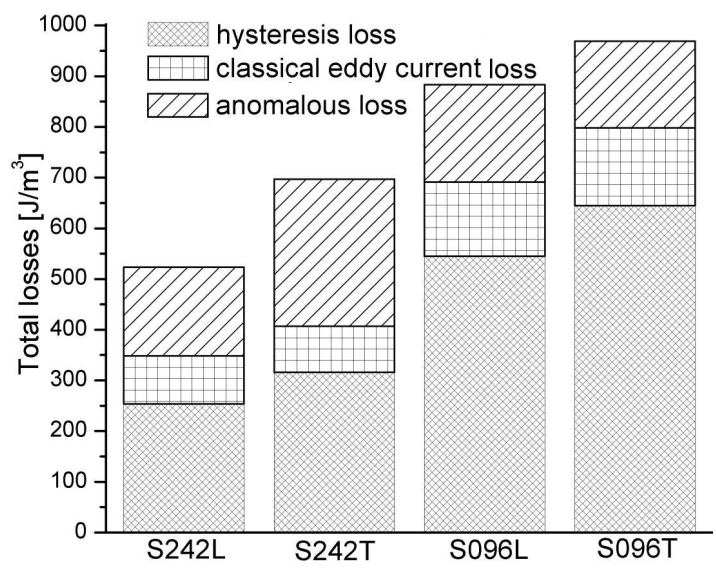

Fig. 2. Total power loss and loss components per cycle for studied $\mathrm{NO}$ electrical steels, $B_{\max }=1.5 \mathrm{~T}$, $f=50 \mathrm{~Hz}$.

Parameters of the samples.

TABLE II

\begin{tabular}{l|c|c|c|c}
\hline \hline Sample & S242L & S242T & S096L & S096T \\
\hline thickness $[\mathrm{mm}]$ & 0.50 & 0.50 & 0.50 & 0.50 \\
length $[\mathrm{mm}]$ & 24.00 & 24.00 & 24.10 & 24.10 \\
width $[\mathrm{mm}]$ & 17.87 & 17.87 & 17.71 & 17.71 \\
density $\left[\mathrm{g} / \mathrm{cm}^{3}\right]$ & 7.70 & 7.70 & 7.80 & 7.80 \\
specific resistivity $[\mu \Omega \mathrm{m}]$ & 0.501 & 0.507 & 0.322 & 0.321 \\
total power loss $\left[\mathrm{J} / \mathrm{m}^{3}\right], 1.5 \mathrm{~T}, 50 \mathrm{~Hz}$ & 523 & 697 & 883 & 969 \\
hysteresis loss $\left[\mathrm{J} / \mathrm{m}^{3}\right], 1.5 \mathrm{~T}$ & 254 & 316 & 545 & 645 \\
classical loss $\left[\mathrm{J} / \mathrm{m}^{3}\right], 1.5 \mathrm{~T}, 50 \mathrm{~Hz}$ & 94 & 91 & 146 & 153 \\
anomalous loss $\left[\mathrm{J} / \mathrm{m}^{3}\right], 1.5 \mathrm{~T}, 50 \mathrm{~Hz}$ & 175 & 290 & 192 & 171
\end{tabular}

\section{Conclusion}

The results clearly show that the varied composition of $\mathrm{Si}$ and grain size affect the core losses in NO electrical steel laminations. NO electrical steel S242 consists of larger grains with smaller magnetic domain size. The difference of the total losses and their constituents shows non-perfect isotropy of both samples. The static losses (major part of total losses at $50 \mathrm{~Hz}$ ) are decreased by larger grain size. Furthermore, dynamic loss is sensitive on the electrical resistivity that influences eddy current in the steel. On the contrary, the anomalous loss of the sample $\mathrm{S} 242 \mathrm{~T}$ is the largest due to larger grain size.

\section{Acknowledgments}

This work was partially supported by the project APVV-LPP-0093/09 and by the ERDF EU grants, under the contract No. ITMS 26220120005.

\section{References}

[1] Y. Oda, M. Kohno, A. Honda, J. Magn. Magn. Mater. 320, 2430 (2008).

[2] S.E. Zirka, Y.I. Moroz, P. Marketos, A.J. Moses, IEEE Trans. Magn. 46, 286 (2010).

[3] G. Bertotti, Hysteresis in Magnetism, Academic Press, San Diego 1998.

[4] M.F. Campos, J.C. Teixeira, F.J.G. Landgraf, J. Magn. Magn. Mater. 301, 94 (2006). 